\title{
Intrinsic Factors Influencing the Infection by Helminth Parasites in Horses under an Oceanic Climate Area (NW Spain)
}

\author{
I. Francisco, ${ }^{1}$ M. Arias, ${ }^{1}$ F. J. Cortiñas, ${ }^{1}$ R. Francisco, ${ }^{1}$ E. Mochales, ${ }^{1}$ V. Dacal, ${ }^{1}$ J. L. Suárez, ${ }^{1}$ \\ J. Uriarte, ${ }^{2}$ P. Morrondo, ${ }^{1}$ R. Sánchez-Andrade, ${ }^{1}$ P. Díez-Baños, ${ }^{1}$ and A. Paz-Silva ${ }^{1}$ \\ ${ }^{1}$ Animal Pathology Department, Epidemiology, Zoonoses and Parasitic Diseases, Veterinary Faculty, \\ University of Santiago de Compostela, 27002-Lugo, Spain \\ ${ }^{2}$ Centro de Investigación y Tecnología Agroalimentaria de Aragón (CITA), Animal Health Division, Avda. Montaña, \\ 93050059 Zaragoza, Spain
}

Correspondence should be addressed to A. Paz-Silva, adolfo.paz@usc.es

Received 9 January 2009; Accepted 4 March 2009

Recommended by Benjamin M. Rosenthal

\begin{abstract}
A coprological survey to determine the influence of some intrinsic factors (breed, age, and sex) on the infection by helminth parasites in equine livestock $(n=418)$ under an oceanic climate area (NW Spain) was conducted. Faecal samples were individually collected and analyzed by the coprological techniques. The main strongylid genera identified were Trichonema and Cyalocephalus spp (small strongyles) and Strongylus and Triodontophorus (large strongyles). The prevalence of gastrointestinal nematode was $89 \%(95 \%$ CI 86,92$)$ and $1 \%$ cestoda $(0,2)$. The percentage of horses with strongyloid parasites was $89 \%(86,92), 11 \%(8,14)$ for Parascaris, and $3 \%(1,5)$ for Oxyuris. The highest prevalence for ascariosis was observed in the youngest horses $(<3$ years $)$, for oxyurosis in the $>10$ years animals, and for strongylosis in the 3-10 years ones. Females were significantly more parasitized than males. A negative correlation between the age and the egg-excretion of ascarids and strongyles was recorded. The autochthonous and the English Pure Blood horses were the most parasitized. We concluded that the infections by helminths, especially the strongyloids, are significantly common in the region, so that greater importance should be given to this situation.
\end{abstract}

Copyright ( 2009 I. Francisco et al. This is an open access article distributed under the Creative Commons Attribution License, which permits unrestricted use, distribution, and reproduction in any medium, provided the original work is properly cited.

\section{Introduction}

The horse industry is increasing because of its diversity, and involves business, sport, gaming, entertainment, or recreation. The raising of horses plays a significant role, due to the high number of animals for leisure, which has generated several direct jobs, such as those needed for handling and the sanity of the animals.

Nowadays, horses are being used in wild pastures and countries for the forest management, utilizing unwanted vegetation for production. For this reason, this industry deserves the attention of the general public and the governments also. This new situation requires more information about the sanitary status of these animals, and the appropriate measures for ensuring the horses are in an adequate fitness condition. Among the diseases affecting horses, helminth infections are much extended [1].

An oceanic climate (also called marine west coast climate and maritime climate) is the climate typically found along the west coasts at the middle latitudes of all the world's continents and in southeastern Australia. Oceanic climates are characterized by a narrower annual range of temperatures than are encountered in other places at a comparable latitude and do not have the extremely dry summers of Mediterranean climates. Under those conditions, survival of parasitology resistant forms is enhanced, enabling thus the possibility for infection throughout the year.

Several investigations have shown the effect of some factors on the infection by parasites in horses. Osterman Lind et al. [2] and Larsen et al. [3] observed the highest output of strongyle eggs in animals aged 2-3 years from Sweden. Bucknell et al. [4] reported that in Australia cyathostomes were more prevalent in young horses, and $P$. equorum was found exclusively in horses less than 2 years of age, and the highest mean intensity of infection for Anoplocephala perfoliata was in those horses. Lyons et al. [5] obtained similar results in equids from Kentucky (USA). 
TABLE 1: Distribution of the fecal samples from horses under an oceanic climate area (NW Spain) according to their breed, sex, and age.

\begin{tabular}{|c|c|c|c|c|c|c|c|c|c|}
\hline & \multicolumn{5}{|c|}{ Female } & \multicolumn{3}{|c|}{ Male } & Total \\
\hline \multirow{2}{*}{ Breed } & \multicolumn{8}{|c|}{ Age (years) } & \\
\hline & $<3$ & $3-10$ & $>10$ & Total & $<3$ & $3-10$ & $>10$ & Total & \\
\hline $\mathrm{CDE}$ & 4 & 8 & 7 & 19 & 3 & 4 & 2 & 9 & 28 \\
\hline PRE & 1 & 6 & 5 & 12 & 3 & 2 & 5 & 10 & 22 \\
\hline PSI & 15 & 40 & 20 & 75 & 3 & 5 & 0 & 8 & 83 \\
\hline PRG & 40 & 129 & 55 & 224 & 16 & 37 & 8 & 61 & 285 \\
\hline Total & 60 & 183 & 87 & 330 & 25 & 48 & 15 & 88 & 418 \\
\hline
\end{tabular}

Nevertheless, there is a lack of knowledge about the influence of breed or sex on the infection by helminth parasites in horses from oceanic climate areas.

This study reports the effect of various intrinsic factors (breed, age, sex) on the equine infection by helminth parasites. Fecal samples were individually collected form 418 horses in an oceanic climate area (NW Spain) and analyzed by the coprological flotation, sedimentation, and migration techniques. Coprocultures were also done to identify the main strongylid genera affecting the horses.

\section{Material and Methods}

2.1. Horses. Between April and September 2007, fecal samples from the rectum of 418 horses from NW Spain were collected. According to the breed, four groups were established (Table 1): Spanish Sport Horse (SSH), Spanish Pure Breed (SPB), English Pure Breed (EPB) and the autochthonous Pura Raza Galega (PRG). By considering the age, horses were divided into three groups: G-1 ( $<3$ years old), G-2 (3-10), and G-3 (>10) (Table 1).

2.2. Study Design. Although some interesting information about horses management as hygienic conditions, treatment history, and so forth would be helpful to explain the results, it was not possible to achieve in many cases, so we decided not to include it in the current paper. Many samples were collected from horses under an extensive management, and ask those questions to the owners was not possible.

For that reason, the impossibility for ensuring the collection of all data belonging to the total population limited us to the analysis of the factors possibly involved in the infection of equines by helminth parasites. The factors we analyzed corresponded to parameters which can be observed and measured for us in all cases.

The influence of climatic conditions on the dynamics of egg expulsion has been reported [6]. Nevertheless, by considering that the main goal in the current work was to gain more information about the presence of helminth infection in horses and the difficulty in taking more than one fecal sample from each animal in several cases, the data presented here must be comprehended as a coprological survey.
2.3. Coprological Analysis. The observation of parasitic forms in the feces of the horses was evaluated by using the coprological flotation, sedimentation, and migration techniques [7]. Five grams of each fecal sample were processed (in duplicate) by the flotation, sedimentation, and migratory techniques [8], with a sensitivity of 10 eggs per gram of feces (EPG).

The laboratory technician conducting the microscope analysis was also blinded to the study design of the selection of the stool specimens.

2.4. Genera Identification. Since it is not possible to distinguish strongyle eggs of different species morphologically, fecal samples are cultured for $10-14$ days at $20-25^{\circ} \mathrm{C}$ to allow the development of L3s, which may be collected by means of the Baermann procedure $[6,9]$. Genera were identified according to Lichtenfels [10].

2.5. Statistical Analysis. By taking account that the egg elimination is not normally distributed, statistical analysis was done by means of the nonparametric Kruskal-Wallis and Mann-Whitney $U$ two-sided tests $(\alpha=0.05)$, and significant differences were considered when $p<.05$. The descriptive parameters were the EPG quartiles 1, 2, and 3. All tests were done using SPSS for Windows (14.1).

Prevalences were expressed as the percentage and the 95\% Confidence Interval (CI).

The existence of correlation among the different parameters was assessed by using nonparametric Spearman's rank correlation test.

\section{Results}

3.1. Identification of Helminth Parasites. Eggs from gastrointestinal nematoda and cestoda were observed in the feces of the horses. No eggs from trematoda or lungworm larvae were obtained.

The analysis of the gastrointestinal eggs showed that the horses were parasitized by Parascaris equorum, Strongyles, and Oxyuris equi. By means of the coprocultures, we identified Cyathostominea and Gyalocephalus spp (small strongyles) and Strongylus and Triodontophorus (large strongyles).

No differences in the genera of strongyles identified according to breed, age, or sex were recorded.

3.2. Prevalence of Helminth Parasites. Eighty nine percent $(95 \%$ CI 86,92$)$ of the samples had gastrointestinal eggs and $1 \%(0,2)$ cestoda. The prevalence of horses passing Parascaris eggs by feces was $11 \%(8,14), 88 \%(85,91)$ strongyles, and $3 \%(1,5)$ oxyurids.

As drawn in Table 2, the highest prevalence of parascariosis was obtained in the youngest animals, English Pure Blood horses and females. No Parascaris eggs were observed in Sport Spanish Horse animals. Significant differences were obtained by considering the age, breed, and sex of the animals.

The prevalence of strongyles was higher in G-1 and G2, horses belonging to the autochthonous PRG breed and 
TABle 2: Prevalences of helminth parasites in 418 horses from an oceanic climate area (NW Spain). Results are expressed as the percentage and the 95\% Confidence Interval (CI). Spanish Sport Horse (SSH), Spanish Pure Breed (SPB), English Pure Breed (EPB), autochthonous Pura Raza Galega (PRG).

\begin{tabular}{|c|c|c|c|c|c|}
\hline & & Ascarids & Strongyles & Oxyurids & Cestoda \\
\hline \multirow{5}{*}{ Age } & $<3$ & $\begin{array}{c}22 \\
(18,26)\end{array}$ & $\begin{array}{c}93 \\
(90,96)\end{array}$ & $\begin{array}{c}1 \\
(0,2)\end{array}$ & 0 \\
\hline & $3-10$ & $\begin{array}{c}6 \\
(4,8)\end{array}$ & $\begin{array}{c}91 \\
(88,94)\end{array}$ & $\begin{array}{c}2 \\
(1,3)\end{array}$ & $\begin{array}{c}2 \\
(1,3)\end{array}$ \\
\hline & $>10$ & $\begin{array}{c}12 \\
(9,15)\end{array}$ & $\begin{array}{c}81 \\
(77,85)\end{array}$ & $\begin{array}{c}6 \\
(4,8)\end{array}$ & $\begin{array}{c}1 \\
(0,2)\end{array}$ \\
\hline & $\chi^{2}$ & 15.842 & 8.732 & 5.584 & 2.228 \\
\hline & $p$ & 0.001 & 0.0013 & 0.061 & 0.328 \\
\hline \multirow{6}{*}{ Breed } & SSH & 0 & 0 & 0 & 0 \\
\hline & SPB & $\begin{array}{c}5 \\
(3,7)\end{array}$ & $\begin{array}{c}19 \\
(15,23)\end{array}$ & 0 & 0 \\
\hline & $\mathrm{EPB}$ & $\begin{array}{c}34 \\
(29,39)\end{array}$ & $\begin{array}{c}98 \\
(97,99)\end{array}$ & $\begin{array}{c}5 \\
(3,7)\end{array}$ & $\begin{array}{c}1 \\
(0,2)\end{array}$ \\
\hline & PRG & $\begin{array}{c}5 \\
(3,7)\end{array}$ & 100 & $\begin{array}{c}2 \\
(1,3)\end{array}$ & $\begin{array}{c}2 \\
(1,3)\end{array}$ \\
\hline & $\chi^{2}$ & 64.960 & 366.936 & 2.87 & 0.976 \\
\hline & $p$ & 0.001 & 0.001 & 0.412 & 0.807 \\
\hline \multirow{4}{*}{ Sex } & Male & $\begin{array}{c}12 \\
(9,15)\end{array}$ & $\begin{array}{c}90 \\
(87,93)\end{array}$ & $\begin{array}{c}3 \\
(1,5)\end{array}$ & $\begin{array}{c}2 \\
(1,3)\end{array}$ \\
\hline & Female & $\begin{array}{c}2 \\
(1,3)\end{array}$ & $\begin{array}{c}84 \\
(80,88)\end{array}$ & 0 & 0 \\
\hline & $x^{2}$ & 7.244 & 3.333 & 2.799 & 1.508 \\
\hline & $p$ & 0.007 & 0.068 & 0.094 & 0.219 \\
\hline
\end{tabular}

females. No positive cases were recorded in the Sport Spanish horses. Significant differences were observed by taking into account the age and the breed of the animals.

Table 2 reflects that the greatest percentage of horses with oxyurids corresponded to the oldest animals (G-3), English Pure Blood, and females. No eggs were observed in males or in SSH animals.

Finally, the highest prevalence of horses passing cestode eggs by feces was obtained in the equids from the G-2 (310 years), autochthonous (PRG), and females, although these differences were not significant.

Spearman's rank test showed a statistical negative correlation between the age of the horses and the prevalence of ascarids and strongyles $(r=-0.141, p=0.005$ and $r=-0.143, p=0.004$, resp.). Likewise, a weak and positive correlation between age and prevalence of pinworms was matched $(r=0.113,0.023)$.

3.3. Intensity of Infection. The results of the egg-excretion are summarized in Table 3. The highest number of Parascaris eggs was observed in the foals, autochthonous horses
TABle 3: Helminth eggs per gram of feces (EPG) in 418 horses from an oceanic climate area (NW Spain). Spanish Sport Horse (SSH), Spanish Pure Breed (SPB), English Pure Breed (EPB); autochthonous Pura Raza Galega (PRG). Results are expressed as EPG quartiles 1, 2, and 3 (Q1, Q2, and Q3, resp.).

\begin{tabular}{|c|c|c|c|c|c|c|}
\hline & & Statistics & Ascarids & Strongyles & Oxyurids & Cestoda \\
\hline \multirow{11}{*}{ Age } & \multirow{3}{*}{$<3$} & Q1 & 0 & 100 & 350 & \\
\hline & & Q2 & 50 & 400 & 350 & \\
\hline & & Q3 & 137 & 775 & 350 & \\
\hline & \multirow{3}{*}{$3-10$} & Q1 & 0 & 100 & 112 & 50 \\
\hline & & Q2 & 0 & 380 & 150 & 50 \\
\hline & & Q3 & 50 & 750 & 3225 & 150 \\
\hline & \multirow{5}{*}{$>10$} & Q1 & 0 & 100 & 100 & 50 \\
\hline & & Q2 & 0 & 200 & 100 & 50 \\
\hline & & Q3 & 50 & 500 & 325 & 50 \\
\hline & & $\chi^{2}$ & 14.781 & 10.500 & 1.560 & 0.2 \\
\hline & & $p$ & 0.001 & 0.005 & 0.458 & 0.655 \\
\hline \multirow{14}{*}{ Breed } & \multirow{4}{*}{$\mathrm{SSH}$} & Q1 & & & & \\
\hline & & Q2 & & & & \\
\hline & & Q3 & & & & \\
\hline & & Q1 & & 25 & & \\
\hline & \multirow[t]{2}{*}{ SPB } & Q2 & & 50 & & \\
\hline & & Q3 & & 725 & & \\
\hline & \multirow{3}{*}{ EPB } & Q1 & 0 & 413 & 100 & 50 \\
\hline & & Q2 & 0 & 650 & 150 & 50 \\
\hline & & Q3 & 50 & 1275 & 150 & 50 \\
\hline & \multirow{5}{*}{ PRG } & Q1 & 0 & 100 & 100 & 50 \\
\hline & & Q2 & 0 & 300 & 225 & 50 \\
\hline & & Q3 & 100 & 700 & 1362 & 150 \\
\hline & & $\chi^{2}$ & 3.450 & 148.841 & 0.165 & 0.2 \\
\hline & & $p$ & 0.327 & 0.001 & 0.684 & 0.655 \\
\hline \multirow{8}{*}{ Sex } & \multirow{3}{*}{ Male } & Q1 & & 50 & & \\
\hline & & Q2 & & 150 & & \\
\hline & & Q3 & & 600 & & \\
\hline & \multirow{5}{*}{ Mare } & Q1 & 0 & 100 & 100 & 50 \\
\hline & & Q2 & 0 & 351 & 150 & 50 \\
\hline & & Q3 & 50 & 750 & 375 & 100 \\
\hline & & $\chi^{2}$ & 0.364 & 7.942 & & \\
\hline & & $p$ & 0.546 & 0.005 & & \\
\hline
\end{tabular}

(PRG), and males. The Kruskal-Wallis test showed significant differences according to the age of the animals.

As drawing in Table 3, there were reached differences in the egg excretion of small strongyles regarding the breed and sex of the horses. The greatest numbers were observed in the English Pure Blood animals and in females, whereas no elimination was observed in Spanish Sport Horses.

No differences were obtained in the egg elimination of oxyurids and cestoda by considering the age, breed, or sex of the horses. 
By means of Spearman's rank test, a statistical negative correlation between the age of the horses and the elimination of ascarids and strongyles eggs was proved $(r=-0.445, p=$ 0.001 and $r=-0.167, p=0.001$, resp.).

\section{Discussion}

Worldwide, horses are exposed to helminth parasites from different groups resulting in significant morbidity and mortality [11]. The most common helminths of horses include the small and large strongyles, along with tapeworms, ascarids, pinworms, and the lungworms [12]. In the current study, we proved the existence of infection by ascarids, strongyles (small and large) and pinworms in horses from NW Spain, which agrees with data reported by Bucknell et al. [4] in Australia, Romaniuk et al. [13] in Polonia, and Pereira and Vianna [1] in Brazil, in horses housed under differing management schemes.

The main helminth parasites observed were strongyles, in agreement with previous investigations in areas with a similar weather $[1,14,15]$. Likewise, a low prevalence was obtained for tapeworms, although the low sensitivity of the fecal examination techniques in detecting cestode eggs could be the explanation to our results [16]. Meana et al. [17] pointed that the coprological methods have a lower likelihood of diagnosing cestode infection when horses have less than 100 tapeworms.

The lack of flukes and coccidia in the current study provides evidence to back up the rarity of infection by this class of parasite $[1,13]$.

To get more knowledge about the factors influencing infections by helminths in horses, the coprological data were examined by considering the age, breed, and sex of the animals. Only $P$. equorum and strongyles showed any age effect. The values of prevalence and elimination of $P$. equieggs were significantly the highest in horses less than 3 years old, which agrees with Mfitilodze and Hutchinson [18] and Bucknell et al. [4].

The percentage of infection by strongyles was significantly greater in the horses less than 10 years old. It has been proved that age does not influence the cyathostome burdens [19], and Klei and Chapman [20] reported that the naturally acquired immunity against small strongyles slowly develops with age, but remains incomplete. This could be the explanation to the finding of a negative correlation between the age and the infection by ascarids and strongyles.

The conditions of housing and management are usually related to the horse breed. This explains why the autochthonous Pura Raza Galega horses, maintained under extensive forest conditions and receiving an inadequate keeping, attained the highest prevalence of infection by ascarids and strongyles. In addition, no helminth parasites were observed in the fecal samples from Spanish Sport horses, and the Spanish Pure Blood ones were few parasitized. Several studies did not match the influence of the horse breed on the helminthosis $[18,21]$.

It has been shown that helminth infection is ubiquitous in horses with access to pasture. The absence of positive results in the Sport Spanish horses seems to be attributable to a reduced possibility for pasturing and thus to contact to the infective phases (larval 3rd stages for the gastrointestinal nematoda) or to intermediate hosts (oribatids in the case of tapeworms). Another possible explanation could be that these are economically valuable horses, maintained under appropriate hygienic conditions, and receiving periodical veterinary attention. Moreover, the observation of elevated prevalences for gastrointestinal worms in the English Pure Blood and in the Spanish Pure Blood equids was an unexpected result, because of their economic value and the conditions of housing and keeping, similar to the Sport Spanish horses.

Our results showed that sex had influence on the prevalence of ascarids and strongyles, being the females more infected than the males, in agreement with Fikru et al. [21].

This is the first study about the effect of several intrinsic factors on the helminth parasites affecting horses from NW Spain, so the lack of coprological surveys makes more difficult the discussion of the results obtained in the current investigation. It must be taken into account that the presence of seasonal dynamics of egg expulsion influences the results for the intensity of parasitization [6].

The development of coprological surveys provides a very interesting and indispensable tool for knowing the main helminth parasites infecting the horses. In the light of our results we consider that the infections caused by helminths, especially the strongyles, are significantly common in the region of study, so that greater importance should be given to this situation. The elevated prevalence in the English Pure Blood and autochthonous horses underlines the need for the application of appropriate measure to the control of helminth parasites. More information is needed to know the applied ways for the control of parasites in equids, in particular that related to chemoprophylaxis.

\section{Acknowledgments}

This work was supported, in part, by a research grant from the Xunta de Galicia (XUGA, Spain) to I. Francisco and R. Francisco, and by the Projects XUGA PGIDT06RAG26102PR and 07MDS021261PR (Xunta de Galicia, Spain), and complies with the current laws for Animal Health Research in Spain. They are in debt to Mrs. B. Valcárcel for preparing and editing the manuscript.

\section{References}

[1] J. R. Pereira and S. S. S. Vianna, "Gastrointestinal parasitic worms in equines in the Paraíba Valley, State of São Paulo, Brazil," Veterinary Parasitology, vol. 140, no. 3-4, pp. 289-295, 2006.

[2] E. Osterman Lind, J. Höglund, B.-L. Ljungström, O. Nilsson, and A. Uggla, "A field survey on the distribution of strongyle infections of horses in Sweden and factors affecting faecal egg counts," Equine Veterinary Journal, vol. 31, no. 1, pp. 68-72, 1999.

[3] M. M. Larsen, S. Lendal, M. Chriél, S. N. Olsen, and H. Bjørn, "Risk factors for high endoparasitic burden and the efficiency 
of a single anthelmintic treatment of Danish horses," Acta Veterinaria Scandinavica, vol. 43, no. 2, pp. 99-106, 2002.

[4] D. G. Bucknell, R. B. Gasser, and I. Beveridge, "The prevalence and epidemiology of gastrointestinal parasites of horses in Victoria, Australia," International Journal for Parasitology, vol. 25, no. 6, pp. 711-724, 1995.

[5] E. T. Lyons, S. C. Tolliver, and S. S. Collins, "Prevalence of large endoparasites at necropsy in horses infected with Population B small strongyles in a herd established in Kentucky in 1966," Parasitology Research, vol. 99, no. 2, pp. 114-118, 2006.

[6] T. A. Kuzmina, Y. I. Kuzmin, and V. A. Kharchenko, "Field study on the survival, migration and overwintering of infective larvae of horse strongyles on pasture in central Ukraine," Veterinary Parasitology, vol. 141, no. 3-4, pp. 264-272, 2006.

[7] R. P. Herd, "Performing equine faecal egg counts," Veterinary Medicine, vol. 87, pp. 240-244, 1992.

[8] MAFF, Manual of Veterinary Parasitological Laboratory Techniques, Ministry of Agriculture, Fisheries and Food, HMSO, London, UK, 1986.

[9] E. Osterman, Prevalence and control of strongyle nematode infections of horses in Sweden, Doctoral thesis, Swedish University of Agricultural Sciences, Uppsala, Sweden, 2005.

[10] J. R. Lichtenfels, "Helminths of domestic equids: illustrated keys to genera and species with emphasis on North American forms," Proceedings of the Helminthological Society of Washington, vol. 42, pp. 1-92, 1975.

[11] J. E. Hodgkinson, "Molecular diagnosis and equine parasitology," Veterinary Parasitology, vol. 136, no. 2, pp. 109-116, 2006.

[12] B. O'Meara and G. Mulcahy, "A survey of helminth control practices in equine establishments in Ireland," Veterinary Parasitology, vol. 109, no. 1-2, pp. 101-110, 2002.

[13] K. Romaniuk, K. Reszka, and E. Lasota, "Influence of animal breeding manner on the occurrence of internal parasites," Wiadomosci Parazytologiczne, vol. 50, no. 3, pp. 647-651, 2004.

[14] S. Love, D. Murphy, and D. Mellor, "Pathogenicity of cyathostome infection," Veterinary Parasitology, vol. 85, no. 2-3, pp. 113-122, 1999.

[15] E. T. Lyons, T. W. Swerczek, S. C. Tolliver, H. D. Bair, J. H. Drudge, and L. E. Ennis, "Prevalence of selected species of internal parasites in equids at necropsy in central Kentucky (1995-1999)," Veterinary Parasitology, vol. 92, no. 1, pp. 5162, 2000.

[16] C. J. Proudman and G. B. Edwards, "Validation of a centrifugation/flotation technique for the diagnosis of equine cestodiasis," Veterinary Record, vol. 131, no. 4, pp. 71-72, 1992.

[17] A. Meana, M. Luzon, J. Corchero, and M. Gómez-Bautista, "Reliability of coprological diagnosis of Anoplocephala perfoliata infection," Veterinary Parasitology, vol. 74, no. 1, pp. 79-83, 1998.

[18] M. W. Mfitilodze and G. W. Hutchinson, "Prevalence and intensity of non-strongyle intestinal parasites of horses in northern Queensland," Australian Veterinary Journal, vol. 66, no. 1, pp. 23-26, 1989.

[19] C. Collobert-Laugier, H. Hoste, C. Sevin, C. Chartier, and P. Dorchies, "Mast cell and eosinophil mucosal responses in the large intestine of horses naturally infected with cyathostomes," Veterinary Parasitology, vol. 107, no. 3, pp. 251-264, 2002.

[20] T. R. Klei and M. R. Chapman, "Immunity in equine cyathostome infections," Veterinary Parasitology, vol. 85, no. 2-3, pp. 123-136, 1999.
[21] R. Fikru, D. Reta, and M. Bizunesh, "Prevalence of equine gastrointestinal parasites in western high lands of Oromia, Ethiopia," Bulletin of the Animal Health Production in Africa, vol. 53, no. 3, pp. 161-166, 2005. 

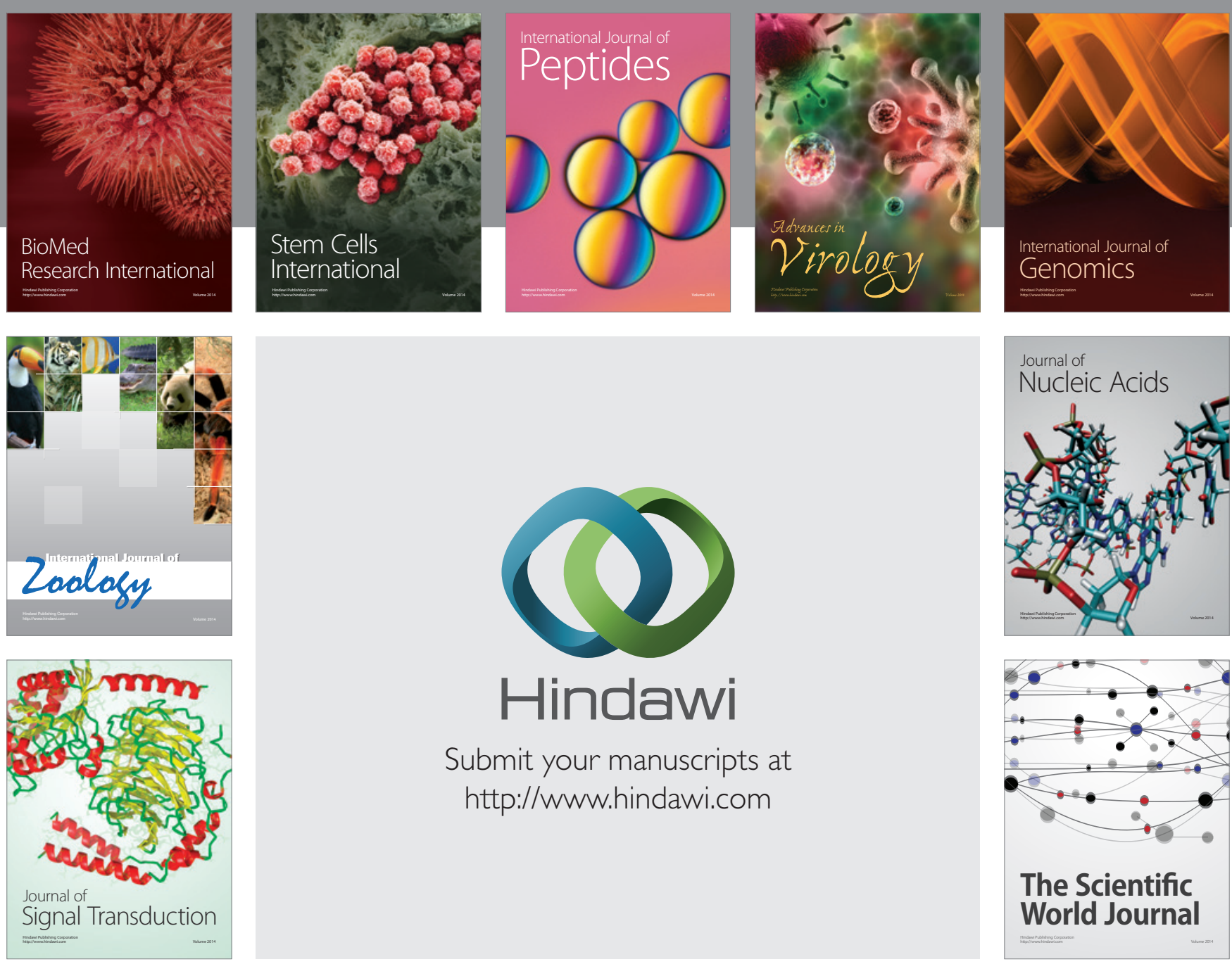

Submit your manuscripts at

http://www.hindawi.com
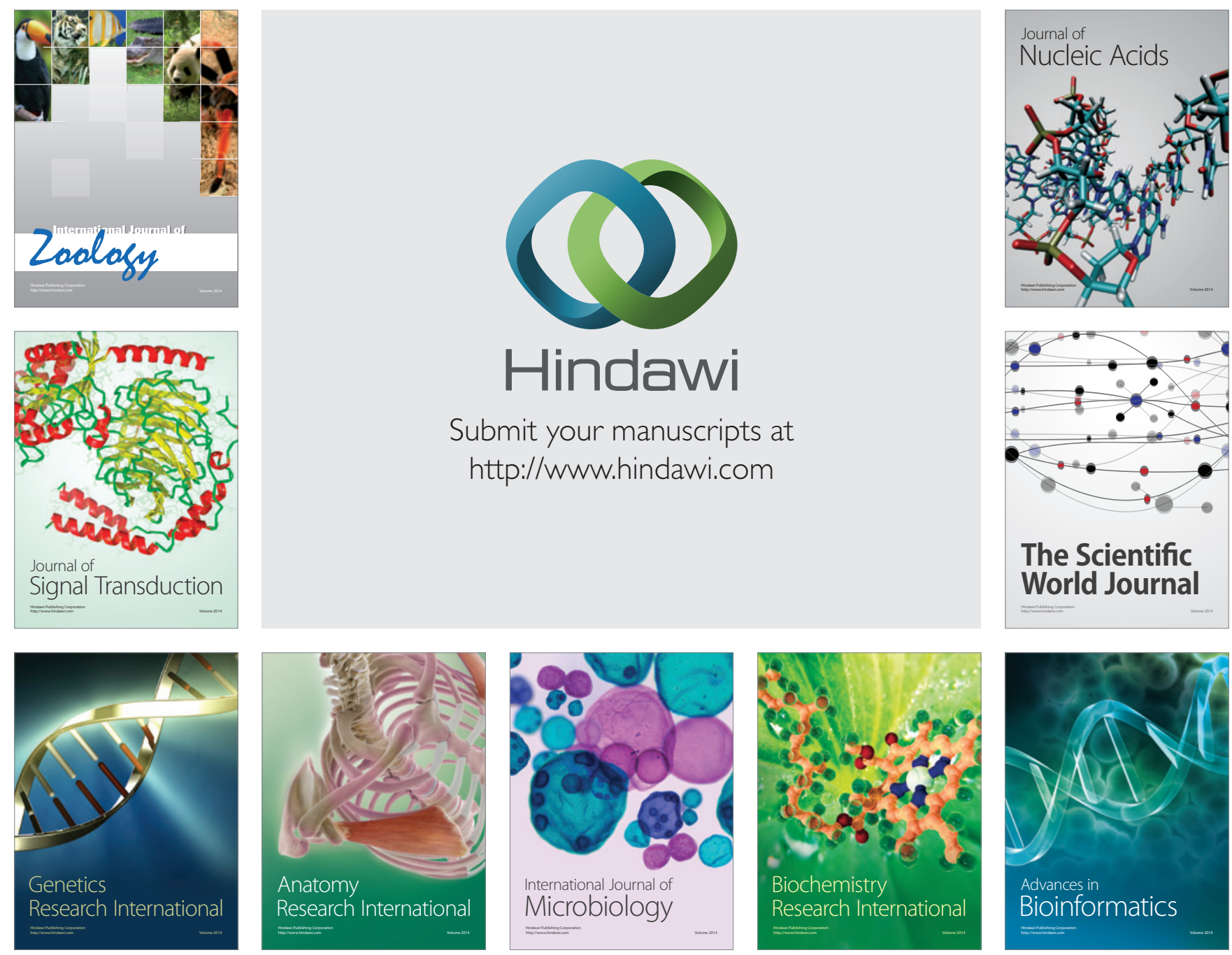

The Scientific World Journal
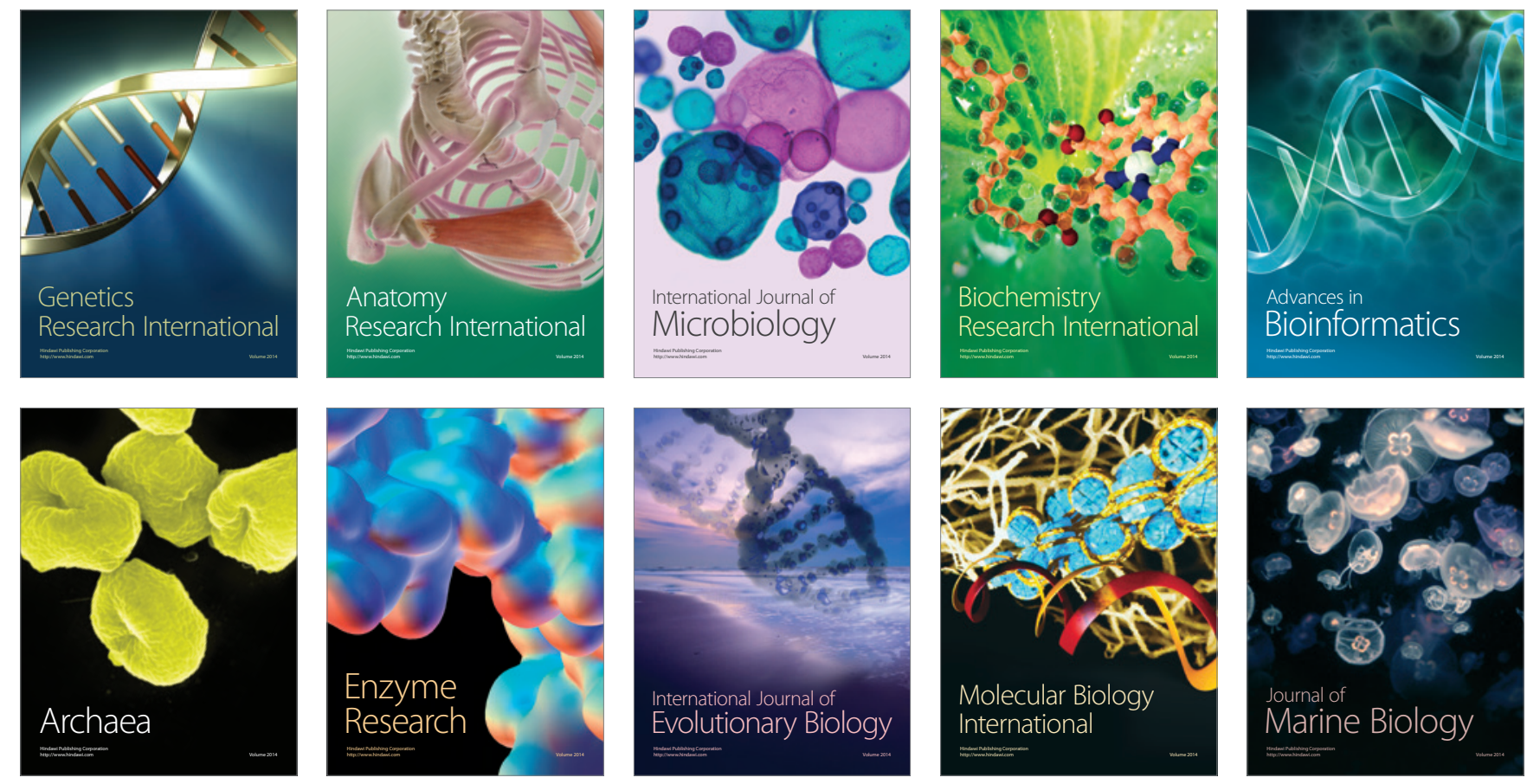